\title{
Quantitative evaluation of industrial and commercial management's promotion to economic growth based on hierarchical constraints
}

\author{
Xiaolong LIN ${ }^{1, *}$ \\ ${ }^{1}$ Huali College Guangdong University of Technology, 511325, Zengcheng, Guangzhou, China
}

\begin{abstract}
In order to improve the quantitative evaluation ability of industrial and commercial management on promoting economic growth, the design method of quantitative evaluation model of industrial and commercial management on promoting economic growth based on hierarchical constraints is proposed. the descriptive statistical analysis method to realize big data fusion mining for quantitative evaluation of business administration's promotion to economic growth is used, and a hierarchical constraint parameter analysis model to realize node deployment model design of hierarchical constraint parameter analysis model is designed, fuzzy control and adaptive feature parameter identification are realized in the process of quantitative evaluation of industrial and commercial administration's promotion to economic growth. Convergence control is realized in the process of quantitative evaluation based on pattern recognition and association distributed fusion. Fuzzy degree identification and optimization prediction of quantitative evaluation of industrial and commercial administration's promotion to economic growth are realized in hierarchical constraint parameter analysis model. The simulation results show that the output accuracy and system stability of the quantitative evaluation of the promotion of business administration to economic growth are good.
\end{abstract}

\section{Introduction}

At present, with the development of macro economy, there are more and more promoting factors of business administration to economic growth. It is necessary to build an optimized quantitative evaluation system of business administration to economic growth, combine with targeted risk management and control measures, explore the related factors that constrain the promotion of business administration to economic growth, and improve the quantitative evaluation ability of business administration to economic growth. Through the analysis of capital cycle factors, financial constraint characteristics and feasibility of project investment, the spatial identification parameters of quantitative evaluation of industrial and commercial management on economic growth are established, and the causes of risks are excavated. Through risk evaluation and multi-source financing, the promotion of industrial and commercial management on economic growth is reduced, and the quantitative evaluation ability of industrial and commercial management on economic growth is improved. Under the network model and big data analysis model, the optimization design of the quantitative evaluation system of industrial and commercial management on economic growth is realized[1].

The design of quantitative evaluation system for the promotion of business administration to economic growth is based on big data mining and feature analysis of risk assessment. By analyzing the panel data of quantitative evaluation of business administration to economic growth, through the fusion of fuzzy parameters of big data and statistical analysis, the quantitative evaluation of business administration to economic growth can be realized[2]. Traditional methods mainly include panel data fusion, multi-source parameter fusion clustering analysis, fuzzy detection method of auto-correlation feature matching, etc., which constructs adaptive variables for quantitative evaluation of industrial and commercial administration's promotion to economic growth, and realizes the quantitative evaluation of industrial and commercial administration's promotion to economic growth through fuzzy parameter clustering analysis. However, traditional methods are not reliable and the level of integration is not good. Therefore, this paper puts forward a design method of quantitative evaluation model for the promotion of business administration to economic growth based on hierarchical constraints. Firstly, a panel data analysis model for quantitative evaluation of business administration's promotion to economic growth is constructed, and descriptive statistical analysis method is adopted to realize big data fusion mining for quantitative evaluation of business administration's promotion to economic growth. Then, a hierarchical constraint parameter analysis model is constructed to realize sensor

* Corresponding author:113503021155@163.com 
node deployment for quantitative evaluation of business administration's promotion to economic growth[3]. The fuzzy control and adaptive feature parameter identification in the process of quantitative evaluation of industrial and commercial administration's promotion to economic growth are realized, and the convergence control in the process of quantitative evaluation of industrial and commercial administration's promotion to economic growth is realized through pattern recognition and associated distributed fusion. Finally, the simulation test analysis shows the superior performance of this method in improving the quantitative evaluation ability of business administration to promote economic growth.

\section{Hierarchical constraint parameter analysis model of panel data analysis and quantitative evaluation of economic growth promotion}

\section{1 panel data analysis of business administration for promoting economic growth}

In order to realize the quantitative evaluation of industrial and commercial administration's promotion to economic growth based on hierarchical constraints, a big data analysis model of industrial and commercial administration's promotion to economic growth is constructed. The characteristics of industrial and commercial administration's promotion to economic growth are analyzed through big data information mining and adaptive feature detection methods, and the statistical feature quantity reflecting the promotion information of industrial and commercial administration to economic growth is extracted[4]. Combined with quantitative regression analysis method, the membership function of quantitative evaluation of industrial and commercial administration's promotion to economic growth under hierarchical constraint parameter analysis model is established as follows:

$$
\alpha_{\text {desira }}^{i}=\alpha_{1} \cdot \frac{\text { Density }_{i}}{\sum_{i} \text { Density }_{i}}+\alpha_{2} \frac{A P_{i}}{A P_{\text {init }}}
$$

Wherein

$$
\left\{\begin{array}{l}
\alpha_{1}+\alpha_{2}=1, \alpha_{1}, \alpha_{2} \in[0,1] \\
\alpha_{2}=\frac{\max _{i}\left(A P_{i}\right)-\min _{i}\left(A P_{i}\right)}{A P_{\text {init }}}
\end{array}\right.
$$

The above formula represents the hierarchical constraint parameter analysis model node U's regional distribution set at monitoring points. By using sparse coefficient degree fusion method, the state characteristic quantity $M_{i}\left[t_{t}>M_{m} \vee M_{n}, M_{m}\left[t_{m}>M_{j}, M_{n}\left[t_{n}>M_{j}\right.\right.\right.$, of industrial and commercial administration's promotion quantitative evaluation of economic growth is obtained, and the promotion fuzzy information management parameters of industrial and commercial administration for economic growth are extracted. Through regular constraints, the time slice $N_{2}(u)=\left\{v \mid d_{G}(u, v)=2\right\}$ allocated by the economic growth promotion quantitative evaluation node is obtained, which represents the orthogonal frequency division characteristic coefficient of the best monitoring node $U$ for industrial and commercial administration's promotion quantitative evaluation of economic growth, a network monitoring model for quantitative evaluation of the promotion of business administration to economic growth is constructed. Combined with the optimization control of transmission channels, the fuzzy feature distribution weight ( $i \neq m \neq n \neq j, a \neq b \neq c$ ) of quantitative evaluation of the promotion of business administration to economic growth is obtained, which is expressed as:

$$
\varepsilon_{t}(i, j)=\frac{\alpha_{t}(i) a_{i j} b_{j}\left(o_{t+1}\right) \beta_{t+1}(j)}{\sum_{i=1}^{N} \sum_{j=1}^{N} \alpha_{t}(i) a_{i j} b_{j}\left(o_{t+1}\right) \beta_{t+1}(j)}
$$

In which, $|\operatorname{Re} v(u)|$ represents the spatial state parameter of industrial and commercial administration's promotion quantitative evaluation of economic growth, and obtains the number of nodes in the receiving end through measurement fusion, representing the deviation of industrial and commercial administration's promotion

quantitative evaluation of economic growth, $a_{i j}$ represents the synchronous node coefficient of the receiving end, $b_{j}$ indicates the similarity feature quantity in the anti-network transmission channel of the quantitative evaluation of the promotion of business administration to economic growth, thus constructing the network distribution model and panel data analysis model of the quantitative evaluation of the promotion of business administration to economic growth, and realizing optimization control by combining the node distribution of the quantitative evaluation system of the promotion of business administration to economic growth[5].

\subsection{Hierarchical constraint parameter analysis model for quantitative evaluation of industrial and commercial management's promotion to economic growth}

On the basis of constructing a panel data analysis model for quantitative evaluation of business administration's promotion to economic growth, a hierarchical constraint parameter analysis model is constructed, and big data fusion mining for quantitative evaluation of business administration's promotion to economic growth is realized by using descriptive statistical analysis method[6]. The hierarchical constraint parameter analysis model for quantitative evaluation of business administration's promotion to economic growth is shown in Figure 1. 


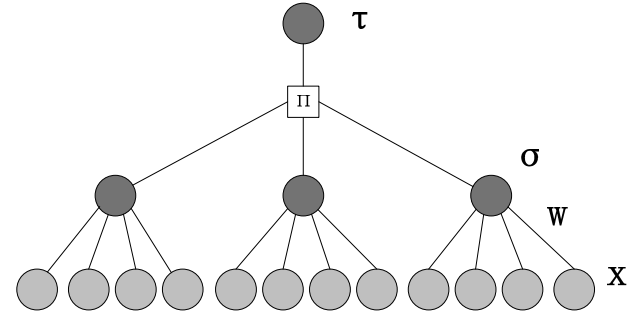

Fig. 1 Hierarchical constraint parameter analysis model for quantitative evaluation of industrial and commercial management's promotion of economic growth

According to the hierarchical constraint parameter analysis model shown in fig. 1, the channel estimation of the multi-functional auxiliary ventilator alarm wireless sensor network monitoring network is realized, and the hierarchical constraint parameter analysis model node deployment model is constructed to realize the quantitative evaluation of the promotion of business administration to economic growth, and the characteristic distribution description of the promotion measurement data of business administration to economic growth is obtained:

$$
\begin{aligned}
\frac{d S_{k}(t)}{d t}= & O_{k}(t)\left(P_{o s 1_{k}}+P_{o s 2_{k}}\right)+T_{k}(t) P_{t s k}-S_{k}(t) P_{s p k} \\
& -S_{k}(t) \beta_{a k}-S_{k}(t)\left(\beta_{u_{k}(t)}+\beta_{l_{k}(t)}\right) \\
& -S_{k}(t)\left(P_{s o 1_{k}}+P_{s o 2_{k}}\right) \\
\frac{d E_{k}(t)}{d t}= & S_{k}(t)\left(\beta_{u_{k}(t)}+\beta_{l_{k}(t)}\right)+X_{k}(t) P_{x e_{k}} \\
& -E_{k}(t) P_{e x_{k}}-E_{k}(t) P_{e t_{k}}-E_{k}(t)\left(P_{e i 1_{k}}+P_{e i 2_{k}}\right) \\
\frac{d P_{k}(t)}{d t}= & T_{k}(t) P_{t p_{k}}+S_{k}(t) P_{s p_{k}} \\
\frac{d T_{k}(t)}{d t}= & I_{k}(t) P_{i t_{k}}+E_{k}(t) P_{e t_{k}}-T_{k}(t) P_{t p_{k}} \\
& -T_{k}(t) P_{t s_{k}}-T_{k}(t)\left(P_{t o 1_{k}}+P_{t o 2_{k}}\right)
\end{aligned}
$$

The statistical feature quantity reflecting the promotion information of business administration to economic growth is extracted, and the game equilibrium model of hierarchical constraint parameter analysis model is obtained by autocorrelation fusion method:

$$
k=\operatorname{Int}\left(\frac{n \bar{Q}}{1-\bar{Q}}\right)+1
$$

In the formula, $\bar{Q}$ is the mean function of big data analysis for quantitative evaluation of industrial and commercial administration on economic growth. By using the method of time-frequency feature analysis, the quantitative decision of quantitative evaluation of industrial and commercial administration on economic growth is made, and the window function of quantitative evaluation of industrial and commercial administration on economic growth is obtained as follows:

$$
\begin{aligned}
f_{\mathrm{lg}-M}(z) & =\left(f_{\mathrm{lg}}(z), f_{\mathrm{lg}-x}(z), f_{\mathrm{lg}-y}(z)\right) \\
& =\left(f_{\mathrm{lg}}(z), h_{x} * f_{\mathrm{lg}}(z), h_{y} * f_{\mathrm{lg}}(z)\right)
\end{aligned}
$$

In the above formula, $f_{\mathrm{lg}}(z)$ indicates the quantitative evaluation level set of industrial and commercial administration's promotion of economic growth, in which the sample characteristics of industrial and commercial administration's promotion of economic growth are distributed as $x_{i}, i=1,2, \cdots, n$, which indicates that industrial and commercial administration's promotion of economic growth quantificationally evaluates several related data items, thus obtaining the best monitoring node positioning quadruple, which is expressed as:

$$
\begin{aligned}
& \max \left\{\left|\operatorname{Ch}(u)-C h(u) \cap C h\left(u_{2}\right)\right|+\left|\operatorname{Ch}(u) \cap C h\left(u_{2}\right)\right|,\right. \\
& \left.\left|C h\left(u_{2}\right)-C h(u) \cap C h\left(u_{2}\right)\right|+\left|\operatorname{Ch}(u) \cap C h\left(u_{2}\right)\right|\right\} \\
& =\max \left\{|\operatorname{Ch}(u)|,\left|C h\left(u_{2}\right)\right|\right\} \leq \Delta
\end{aligned}
$$

In the above formula, $C h(u)$ represents the offset vector of the monitoring and early warning node with the best economic growth promotion.

\section{The promotion of industrial and commercial management to economic growth is quantitatively evaluated and optimized}

\subsection{Industrial and commercial management informationization economic growth promotion quantitative evaluation fuzzy decision-making.}

Constrained feature analysis method is used to construct the horizontal quantitative set of industrial and commercial management informatization economic growth promotion quantitative evaluation, and get the parameter distribution set of individual samples of economic growth promotion evaluation[7]. Fuzzy control and adaptive feature parameter identification in the process of industrial and commercial management promotion quantitative evaluation of economic growth are realized by fuzzy detection and information fusion identification, and the amplitude of parameter distribution meets the following distribution:

$$
p\left(e_{k} \mid v_{k}\right) \sim t_{\left(\tilde{v}_{k}+d_{e}\right)}\left(\tilde{u}_{e \mid v, k}, \tilde{\Sigma}_{e \mid v k}\right)
$$

Constrained variable model for quantitative evaluation of industrial and commercial management's promotion to economic growth is constructed. By using fuzzy learning method, the parameter training set of quantitative evaluation of industrial and commercial management's informatization economic growth is obtained. The model of industrial and commercial management's promotion to economic growth is as follows:

$$
\begin{aligned}
& \tilde{\Sigma}_{e \mid v k}=h_{e \mid v, k}\left(\tilde{\Sigma}_{e e, k}-\tilde{\Sigma}_{v e, k}^{T} \tilde{\Sigma}_{v v, k}^{-1} \tilde{\Sigma}_{v e, k}\right) \\
& h_{e \mid v, k}=\frac{1}{\left(\tilde{v}_{k}+d_{v}\right)} \times\left[\tilde{v}_{k}+\left(v_{k}-\tilde{u}_{v, k}\right)^{T} \tilde{\Sigma}_{v v, k}^{-1}\left(v_{k}-\tilde{u}_{v, k}\right)\right]
\end{aligned}
$$

Wherein, $\tilde{v}_{k}=v_{k}-d+1$ indicates the connectivity of the hierarchical constraint parameter analysis model for quantitative evaluation of economic growth promotion, and uses the association rule mining method to fuse the business administration rate, and the fuzzy fusion results are as follows: 


$$
\tilde{u}_{k}=u_{k}, \quad \tilde{\Sigma}_{k}=\frac{1+V_{11, k}}{\left(v_{k}-d+1\right) V_{11, k}} \Lambda_{k}
$$

Statistical feature analysis is used to quantitatively evaluate the promotion of business administration to economic growth, and combined with the fusion feature analysis of ontology rules, the promotion of business administration to economic growth is quantitatively evaluated and automated early warning is realized[8].

\subsection{Industrial and Commercial Administration's Promotive Quantitative Evaluation Control on Economic Growth}

Combining with the template parameter distribution of industrial and commercial administration's promotion to economic growth, this paper establishes a big data analysis model for quantitative evaluation of industrial and commercial administration's promotion to economic growth, and uses association rule mining method to control the reliability of quantitative evaluation of industrial and commercial administration's promotion to economic growth, and obtains the target quantitative feature distribution set as follows:

$$
\begin{gathered}
y(t)=\int_{-\infty}^{+\infty} h(t-s) x(s) d s \\
W_{y}(t, v)=\int_{-\infty}^{+\infty} W_{h}(t-s, v) W_{x}(s, v) d s
\end{gathered}
$$

Combined with the profitability level of the industrial and commercial management equity market, using the linear regression analysis method, the iterative equation of joint characteristic distribution for quantitative evaluation of the promotion of industrial and commercial management informationization economic growth is obtained as follows:

$$
K_{k+1 / k+1}=\rho_{k} \frac{m_{k}}{m_{k+1}} \Phi_{k} K_{k / k} \Phi_{k}^{T}+\frac{1}{m_{k+1}} \delta K
$$

Where

$$
\delta K=\left[\begin{array}{c|c}
S-\sigma I & z \\
\hline z^{T} & \sigma
\end{array}\right]
$$

Establish an antagonistic network game model for quantitative evaluation of business administration on economic growth, and take the quantitative evaluation level of business administration on economic growth as the decision-making goal, and get the standard quantitative characteristic distribution set of quantitative evaluation of business administration on economic growth as follows:

$$
S T D f_{i, j}=\frac{\text { Freq }_{i, j}}{\max _{l} \text { Freq }_{i, j}}
$$

Among them, the statistical characteristics of the quantitative evaluation of the promotion of business administration to economic growth between $\max _{l}$ Freq $_{i, j}$ are as follows:

$$
\left.\operatorname{Idf} f_{i}=\log \left(\frac{N}{n_{i}}\right)\right)
$$

Then

$$
w_{i, j}=t f_{i, j} \times I d f_{i}
$$

Where, $d_{i}$ and $d_{j}$ are the similarity feature components of the quantitative evaluation of industrial and commercial administration for promoting economic growth[9]. With linear regression analysis, the fluctuation calculation formula of the quantitative evaluation of industrial and commercial administration for promoting economic growth is obtained as follows:

$$
D\left(d_{i}, d_{j}\right)=\frac{d_{i} \cdot d_{j}}{\left\|d_{i}\right\| \times\left\|d_{j}\right\|}
$$

According to the analysis of industrial and commercial management factors, the calculation formula of the equilibrium measurement factor for the quantitative evaluation of the promotion of industrial and commercial management to economic growth is as follows:

$$
D M=\frac{d_{e}+d_{b}+\sum_{i=1}^{n-1}\left|d_{i}-\frac{\sum_{i-1}^{n-1} d_{i}}{n-1}\right|}{d_{e}+d_{b}+(n-1) \frac{\sum_{i=1}^{n-1} d_{i}}{n-1}}
$$

Among them, $d_{e}$ is the scale variable of investment funds and the average fitness of industrial and commercial administration's promotion and quantitative evaluation of economic growth. From the internal and external factors, this paper analyzes the pre-factors of promoting economic growth by industrial and commercial management, and obtains the rule characteristic quantity of differentiated early warning as follows:

$$
\max _{x i, y i, j} \max _{x i, y i, j} T P=\frac{1}{t p}, i, j \in\{0,1, \ldots, v+1\}
$$

Where:

$$
t p=\max \left\{\max _{i \in V} \max _{i \in V}\left(x_{i} \cdot \frac{s i}{\eta p} \sum_{i \in V} x_{i}\right), \max _{(i, j) \in E} \max _{(i, j) \in E}\left(\frac{d_{i, j}\left(x_{i}-x_{j}\right)^{2}}{y_{i, j}}\right)\right\}
$$

According to the above analysis, the optimal early warning control model of business management on economic growth under the risk management system is as follows:

$$
k=\operatorname{Int}\left(\frac{n \bar{Q}}{1-\bar{Q}}\right)+1
$$

In the formula, $\bar{Q}$ is the endogenous control variable of the quantitative evaluation of the promotion of business administration to economic growth. To sum up, through pattern recognition and association distributed fusion, the convergence control in the process of quantitative evaluation of industrial and commercial management's promotion to economic growth is realized. In the hierarchical constraint parameter analysis model, the fuzzy identification and optimization prediction of quantitative evaluation of industrial and commercial management's promotion to economic growth are realized[10]. 


\section{Simulation experiment and result analysis}

In order to verify the application performance of this method in realizing the promotion quantitative evaluation and optimization control of business administration to economic growth, SPSS14.0 statistical analysis software and Matlab are used for simulation test. The number of nodes in the hierarchical constraint parameter analysis model of business administration's promotion quantitative evaluation to economic growth is 120 , the data collection scale is 2000 , the number of big data training samples of business administration's promotion quantitative evaluation to economic growth is 400 , and the statistical analysis variables of economic growth promotion quantitative evaluation are shown in Table 1.

Table 1 Statistical variable analysis of quantitative evaluation of the promotion of business administration to economic growth

\begin{tabular}{ccccc}
\hline Sample & Financial gain & risk ratio & investment scale & Cash flow \\
\hline 1 & 3.34 & 1.276 & 4.78 & 0.533 \\
2 & 6.45 & 1.676 & 14.54 & 0.546 \\
3 & 56.67 & 1.765 & 35.09 & 3.656 \\
4 & 43.65 & 1.653 & 54.42 & 3.667 \\
5 & 55.64 & 0.546 & 57.53 & 4.899 \\
6 & 67.32 & 0.465 & 75.67 & 0.987 \\
7 & 65.87 & 1.665 & 67.65 & 0.866 \\
8 & 65.65 & 1.644 & 75.35 & 0.454 \\
9 & 67.43 & 1.536 & 553.54 & 0.536 \\
10 & 65.55 & 1.547 & 46.34 & 0.546 \\
11 & 67.65 & 0.764 & 78.75 & 0.778 \\
12 & 45.75 & 0.545 & 76.76 & 0.486
\end{tabular}

According to the statistical analysis results in Table 1, the quantitative evaluation of the promotion of business administration to economic growth is realized, and the characteristic distribution of the promotion of business administration to economic growth is shown in Figure 2.

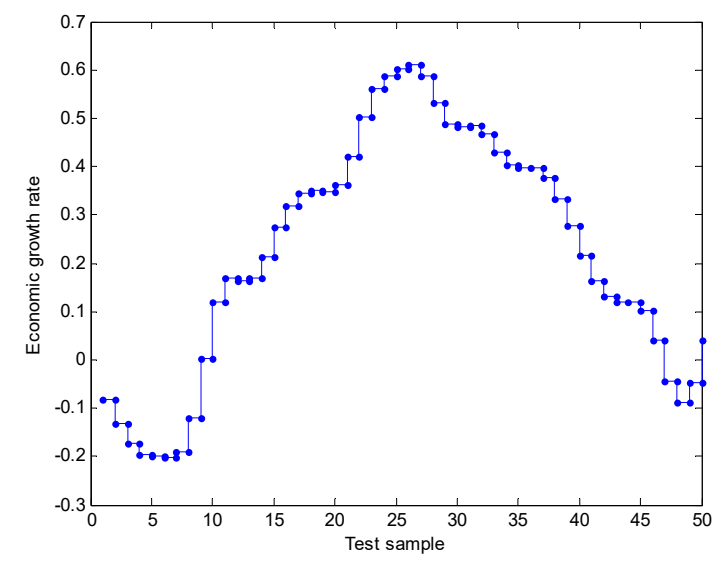

Fig. 2 Characteristic distribution of the promotion of business administration to economic growth
According to the characteristic distribution results of the promotion of business administration to economic growth in Figure 2, the promotion of business administration to economic growth is predicted, and the output of risk assessment is shown in Figure 3.

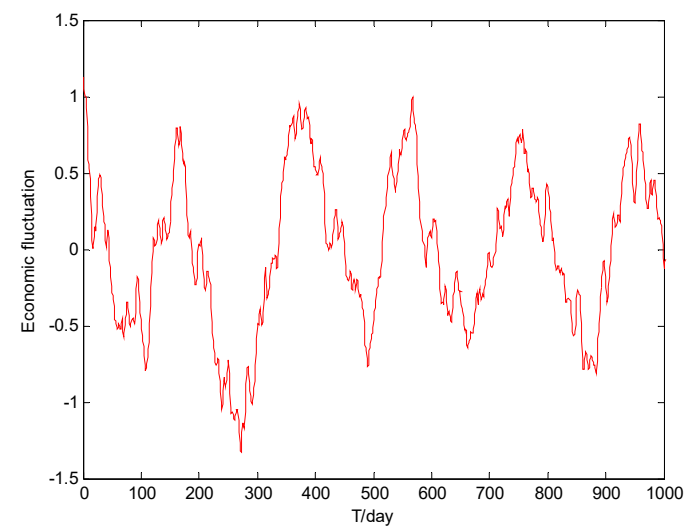

Fig. 3 Output of industrial and commercial management's promotion evaluation of economic growth

By analyzing Figure 3, we know that this method can effectively realize the predictive evaluation of the promotion of business administration to economic growth, and improve the quantitative evaluation ability of business administration to economic growth. Test the reliability of quantitative evaluation of business administration's promotion to economic growth, and get the comparison result as shown in Figure 4.

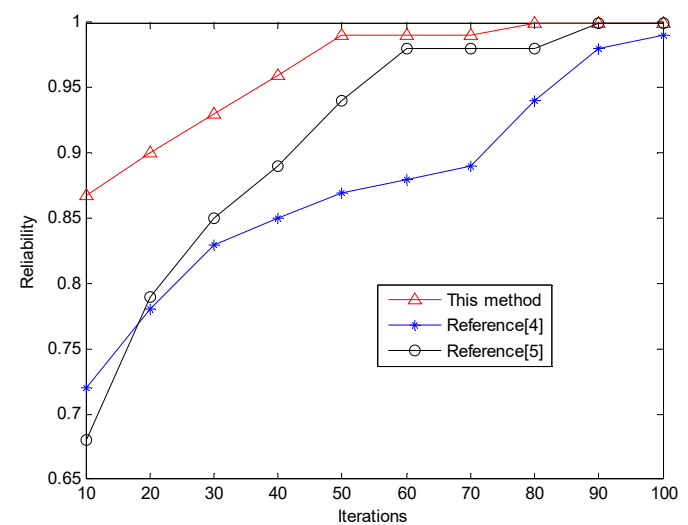

Fig. 4 Promotion of business administration to economic growth and the reliability of quantitative evaluation

According to the analysis of Figure 4, the reliability of quantitative evaluation of the promotion of business administration to economic growth is high.

\section{Conclusions}

In this paper, by analyzing the factors of capital cycle, the characteristics of financial constraints and the feasibility of project investment, the spatial identification parameters of quantitative evaluation of industrial and commercial administration's promotion to economic growth are established, the causes of risks are excavated, the promotion of industrial and commercial administration to 
economic growth is reduced, and the ability of quantitative evaluation of industrial and commercial administration's promotion to economic growth is improved. The fuzzy control and adaptive feature parameter identification in the process of quantitative evaluation of industrial and commercial administration's promotion to economic growth are realized, and the convergence control in the process of quantitative evaluation of industrial and commercial administration's promotion to economic growth is realized through pattern recognition and associated distributed fusion. In the hierarchical constraint parameter analysis model, the fuzzy degree identification and optimization prediction of the quantitative evaluation of the promotion of business administration to economic growth are realized. The analysis shows that this method can effectively realize the predictive evaluation of the promotion of business administration to economic growth, and improve the quantitative evaluation ability of business administration to economic growth.

\section{References}

1. PAN Jizheng. Improvement of accounting method of large scientific research project based on Evolutionary Game Theory[J]. Management Engineer, 2017,22(1):36-40.

2. ZHAO Xiaolin, WU Yipeng, HUANG Huiying,et al. New generation of migrant workers housing purchasing power and the housing sales to inventory constraints relationship model -- Taking Zengcheng area as an example[J]. Management Engineer, 2017,22(1):8-13.

3. WU Y X, WEN X. Short-term stock price forecast based on ARIMA model[J]. Statistics and Decision, 2016(23):83-86.

4. LI X, PENG L, HU Y, SHAO J, et al. Deep learning architecture for air quality predictions[J]. Environmental Science \& Pollution Research, 2016, 23(22):22408-22417.

5. BAI Xuejie,SUN Hongyin,WANG Haifeng.M\&A Behaviors and Market Power ;An Analysis Based on Chinese A-share Enterprises[J].2016,(03):106-113.

6. LIU Hong-kui,WANC Zhi-guo,ZOU Heng-fu.The Effects of Monetary Policy on the Dynamic Process of Short-term Market lnterest Rate--An Empirical Research Based on SHIBOR[J].2016,(02):30-40.

7. Taguchi,H.,Sahoo,P., Nataraj,G. Capital Flows and Asset Prices:Empirical Evidence from Emerging and Developing Economies[J]. International Economics,2015,141(5):1-14

8. An Hui, Ding Zhilong, Gu Yu. Study on the influence factors of liquidity shock risk in the BRICs [J]. International financial research, 2016, 349 (5): 27-37.

9. WANG Zhicheng, XU Quan, ZHAO Wenfa. Some thoughts on the reform of China's financial supervision system $[\mathrm{J}]$. International financial research, 2016, 351 (7): 33-40.

10. Youcef AMIRAT,Arnaud MÜ,NCH. On the Controllability of an Advection-diffusion Equation with Respect to the Diffusion Parameter: Asymptotic Analysis and Numerical Simulations[J]. Acta Mathematicae Applicatae Sinica, English Serie, 2019, 35(1): 54-110. 